\title{
Corrosion of stainless steel components in seawater reverse osmosis desalination plants-investigations on adapted internal cathodic protection
}

\author{
Larché Nicolas ${ }^{1,{ }^{*}}$, Dézerville Philippe ${ }^{2}$, Le Flour Denise ${ }_{1}^{3}$, Vinzio Pascal ${ }^{4}$, Köfler Karl-Heinz ${ }^{4}$, \\ Thierry Dominique ${ }^{1}$
}

${ }^{1}$ Inst Corros, Marine Corros \& Cathod Protect, Brest, France.

${ }^{2}$ Veolia Eau, Direct Tech \& Performance, St Maurice, France.

${ }^{3}$ IFREMER, Lab Comportement Struct Mer, Plouzane, France.

${ }^{4}$ KSB SAS, Gradignan, France.

Corresponding author : Nicolas Larché, email address : nicolas.larche@institut-corrosion.fr philippe.dezerville@veoliaeau.fr ; denise.le.flour@ifremer.fr ; pascal.vinzio@ksb.com

\begin{abstract}
:
Stainless steel is widely used in seawater reverse osmosis units (SWRO) for both good mechanical and corrosion resistance properties. However, many corrosion failures of stainless steel in SWRO desalination units have been reported. These failures may often be attributed to un-adapted stainless steel grade selection and/or to the particular aggressive seawater conditions in "warm" regions (high ambient temperature, severe biofouling, etc.). Cathodic protection (CP) is a well-known efficient system to prevent corrosion of metallic materials in seawater. It is successfully used in the oil and gas industry to protect carbon steel structures exposed in open-sea. However, the specific service conditions of SWRO units may seriously affect the efficiency of such anti-corrosion system (high flow rates, large stainless steel surfaces affected by biofouling, confinement limiting protective cathodic current flow, etc.). Hence, CP in SWRO units should be considered with special care and modeling appears as useful tool to assess an appropriate CP design. However, there is a clear lack of CP data that could be transposed to SWRO service conditions (i.e. stainless steel, effect of biofouling, high flow rate, etc.). From this background a Join Industry Program was initiated including laboratory exposures, field measurements in a full scale SWRO desalination plant, and modeling work using PROCOR software.

The present paper reviews the main parameters affecting corrosion of stainless steel alloys in seawater reverse osmosis units. CP on specific stainless steel devices was investigated in order to assess its actual efficiency for SWRO units. Severe environmental conditions were intentionally used to promote corrosion on the tested stainless steel products in order to evaluate the efficiency of CP. The study includes a modeling work aiming at predicting and designing adapted CP protection to modeled stainless steel units. An excellent correlation between modeling work and field measurements was found.
\end{abstract}

Keywords : Corrosion, Seawater reverse osmosis, Stainless steels, Cathodic protection 


\section{1-Introduction}

Due to high chloride content, high pressures and dissolved oxygen content at saturation, material selection for seawater reverse osmosis (SWRO) units requires special attention to avoid mechanical and/or corrosion failures. In these demanding applications, the conventional material selection has been typically stainless steels with "sufficient" pitting resistant equivalent number. However, many cases of corrosion failures of stainless steel in SWRO desalination units have been reported. In most cases, the cause of the failure was attributed to the use of not enough alloyed grades for seawater handling applications such as UNS S31603 (316L), S 31703 (317L) and N08904 (904L), which are highly susceptible to pitting and crevice corrosion in seawater at ambient temperatures [1]. More alloyed stainless steels materials such as superaustenitic UNS S31254 and superduplex UNS S32750 are also susceptible to pitting and crevice corrosion in seawater [2-4] and the operational corrosion risk will highly depend on the service conditions (e. g. temperature, biofilms, chlorination, etc.), the metallurgy of the product (wrought or cast alloys) and on the geometrical configuration of the confined zones in contact with seawater [5-7].

When the metallic material is not adapted, corrosion may propagate very quickly and two main solutions are generally considered:

- Change the material to a corrosion resistant alloy

- Implement a system or a treatment to stop or control the existing corrosion

The first solution may be extremely costly and often not possible. For the second option, one of the most efficient and economical solution to prevent the propagation of the degradation on metallic materials is to apply an adapted cathodic protection. It is well known that "lowcorrosion resistant” metallic materials (e. g. carbon steels) can be used in seawater handling systems under appropriate cathodic protection. The principle of the cathodic protection (CP) is to negatively polarize a metal in order to lower its corrosion potential below its immune domain (i. e. potential for which the corrosion rate is considered negligible). Cathodic protection design of offshore structures made of carbon steels is rather well documented in the literrature and in standards [8-11]. However, in the particular service conditions of seawater reverse osmosis desalisation plants (e. g. high pressures, high velocities, confinements, treated seawater, stainless steels structures with large metallic area, etc.), the actual efficiency of cathodic protection may be strongly affected. From the literature and the existing standards, there is a lack of data for cathodic protection adapted to the materials (e. g. stainles steels), the designs (e. g. Internal confined circulation of seawater) and the operating conditions (e. g. chlorination, high pressure) used in desalination units. Thus it appeared unavoidable to collect and analyze data from both laboratory and field tests in order to define an adapted cathodic protection design for specific units of SWRO process. In a previous paper the corrosion risks of stainless steels and copper based alloy was presented toghether with laboratory and field testing for investigations on adapted cathodic protection systems [12]. First results from modeling with PROCOR ${ }^{\mathrm{TM}}$ were given and showed very good correlation with both laboratory and field results. In the present paper the influence of service conditions on cathodic protection of stainless steels units is further detailled and criteria for cathodic protection of selected stainless steels are given.

\section{2-Experimental}




\section{$\underline{\text { 2.1-Investigations on cathodic protection criteria for stainless steels }}$}

To investigate the criteria for cathodic protection of stainless steels, the tested materials were:

- $\quad$ Rolled UNS S32205 duplex stainless steel (plate material)

- Cast UNS J92205 duplex stainless steel (plate material)

- UNS S31603 stainless steel (butterfly valve)

The composition of the used alloys is presented in Table 1.

Table 1: Chemical composition (weight \%) of the tested stainless steels

\begin{tabular}{|l|l|l|l|l|l|l|l|}
\hline UNS. & $\mathrm{C}$ & $\mathrm{Fe}$ & $\mathrm{Ni}$ & $\mathrm{Cr}$ & $\mathrm{Mo}$ & $\mathrm{Mn}$ & $\mathrm{N}$ \\
\hline S32205 (wrought) & 0.016 & Bal. & 6.08 & 22.61 & 3.4 & 1.27 & 0.185 \\
\hline $\begin{array}{l}\text { J92205 (cast) } \\
\text { (CD3MN) }\end{array}$ & 0.020 & Bal. & 5.20 & 21.91 & 2.71 & 1.52 & 0.15 \\
\hline S31603 & $<0.020$ & Bal. & 12.2 & 17.2 & 2.2 & - & - \\
\hline
\end{tabular}

To assess cathodic protection criteria to prevent crevice corrosion, CREVCORR-type assemblies were used to simulate crevice configurations [13-14]. Crevice formers were made of polyvinylidene fluoride (PVDF), all fasteners were made of titanium grade 2 and electrically isolated from the tested specimen, and disc springs were used to keep a measurable and constant pressure between the crevice formers and the specimen. The principle of the CREVCORR assembly is illustrated in Figure 1.
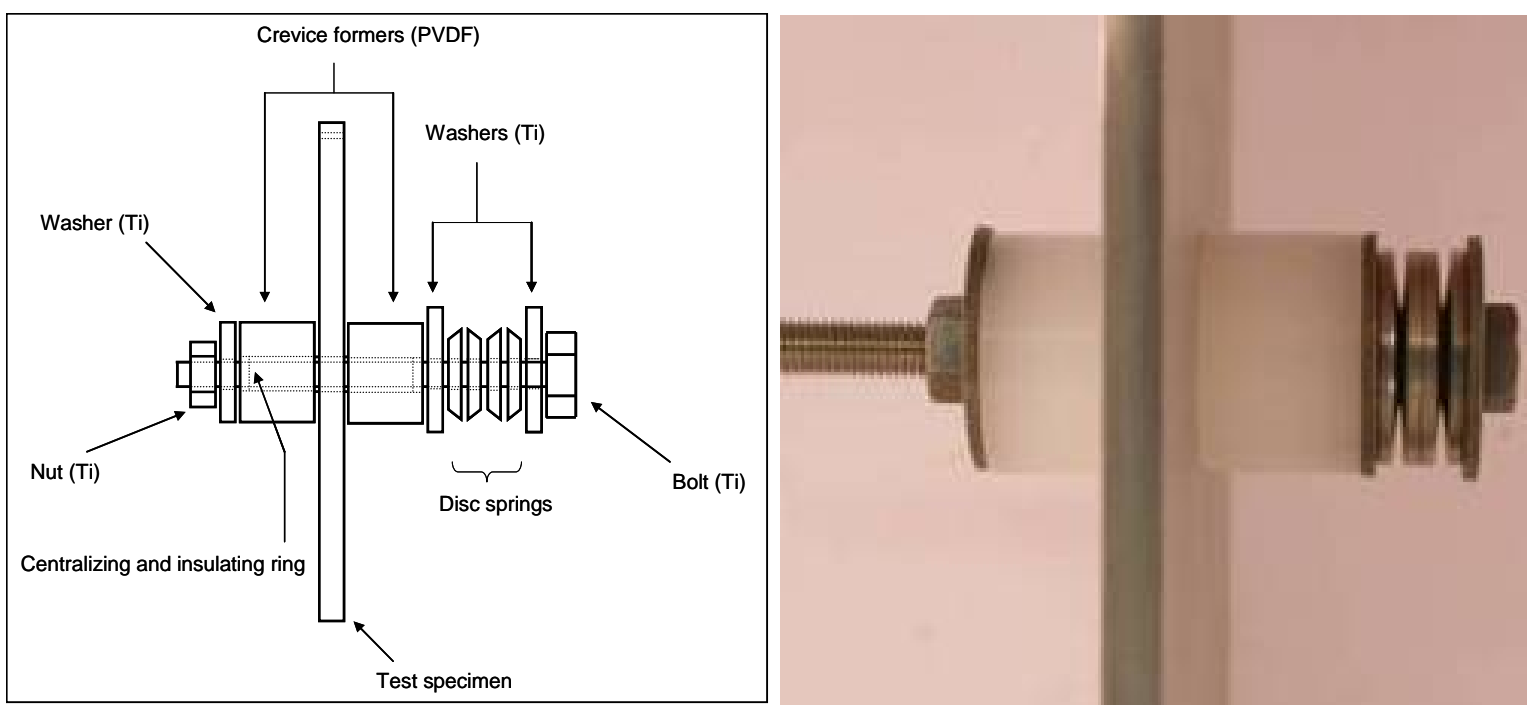

Figure 1: Schematic representation and picture of the crevice assembly (based on CREVCORR assembly)

The open-circuit potential (OCP) of the tested specimens was measured and recorded. The reference electrodes were gel Ag/AgCl-KCl from Metler Toledo (ref. 363 DXK S8/120), weekly calibrated with Saturated Calomel Electrode (SCE) from Radiometer. Data loggers EPC8 from NKE with high impedance $\left(>10^{11} \Omega\right)$ were used to record the open-circuit potential of the tested specimens during exposure. Cathodic currents were measured with potential drop 
measurements across resistors. Data loggers from At40g from MITEC Instruments were used for this purpose.

Remark: The potential of SCE are very close to the potential of the pseudo-reference $\mathrm{Ag} / \mathrm{AgCl}$-seawater $( \pm 5 \mathrm{mV})$ generally found in the literature. In the present work all results are presented versus SCE reference.

All Exposures were performed in natural seawater heated at $30^{\circ} \mathrm{C}$, directly and continuously taken from the bay of Brest. Samples were exposed at least 1 month and until stabilization of both potential and current.

\section{$\underline{\text { 2.2-Polarization curves for stainless steels in SWRO service conditions }}$}

The following devices were used for laboratory testing:

- Multistage pumps made of 316L grade stainless steel (UNS S31603), working at pressures from 0 to 6 bar

- Butterfly valves made of 316L grade stainless steel (UNS S31603)

- $\quad$ A one inch diameter superduplex 2507 pipe (UNS S32750), length = $2 \mathrm{~m}$

The composition of the tested alloys are given in Table 2. For pump and valve exposure tests, the stainless steel 316L was selected as a "low grade" stainless steel reference to assess the actual efficiency of cathodic protection on a grade which is known not to resist localized corrosion in natural seawater.

Table 2: Composition of the tested devices for laboratory exposures

\begin{tabular}{|c|c|c|c|c|c|c|c|c|}
\hline & UNS. & Fe & Cu & Ni & Cr & Al & Mo & other \\
\hline $\begin{array}{l}\text { 316L- } \\
\text { Valve }\end{array}$ & S31603 & bal. & - & 12.0 & 16.8 & - & 2.5 & - \\
\hline $\begin{array}{l}\text { 316L- } \\
\text { pump }\end{array}$ & S31603 & bal. & - & 12.2 & 17.2 & - & 2.2 & - \\
\hline $\begin{array}{l}\mathbf{2 5 0 7}- \\
\text { SDSS }\end{array}$ & S32750 & bal. & 0.12 & 6.9 & 25.1 & - & 4.1 & $\mathrm{~N}=0.28$ \\
\hline
\end{tabular}

\section{Laboratory measurements}

The pumps were mounted as shown in Figure 2 with possibility to implement cathodic protection system and a permanent reference electrode for the monitoring of the potential. The pumps were controlled with a PumpDrive system, allowing pressure and flow velocity control. Both a cathodic protection system with galvanic anode and impressed current with rectifier were implemented with the proposed set-up. All the plastic piping system was made of pressure resistant Corzan CPVC provided by Lubrizol Advanced Materials. 

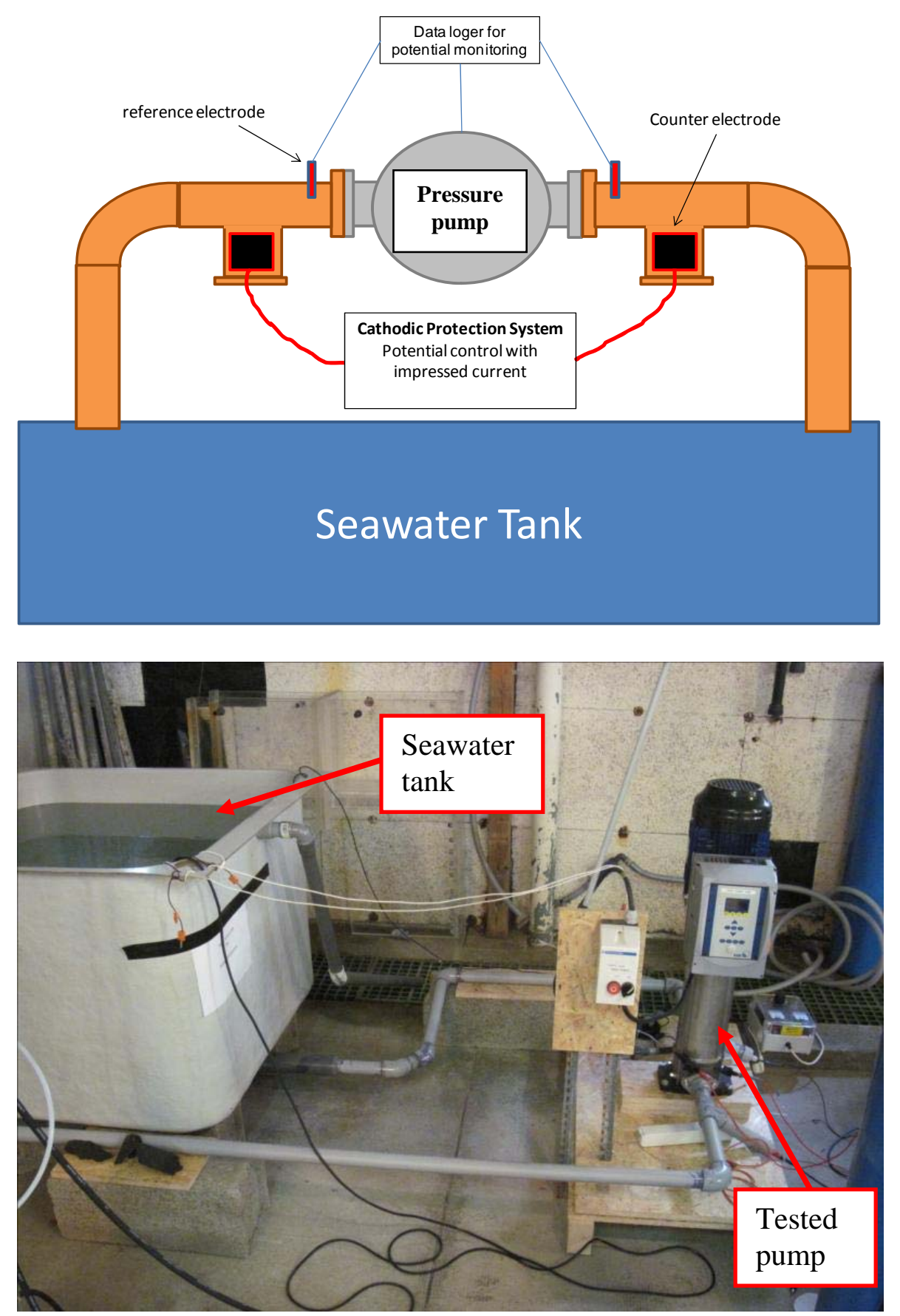

Figure 2: Schematic drawing and photograph of the monitored 316L stainless steel pump

In a separated seawater loop, the 2 m-long pipe was monitored by introducing 9 reference electrodes (through specifically designed access fittings) along the pipe (i. e. at different distance from the anode). A circulation pump allowed to control the water flow rate inside the tube. A schematic drawing and a photograph of the set-up is given in Figure 3. Both a cathodic protection system with galvanic anode and impressed current with rectifier were implemented. In parallel, superduplex stainless steel coupons with plate geometry $(50 \mathrm{~mm} \mathrm{x}$ $50 \mathrm{~mm}$ ) were exposed in the seawater loop at the outlet of the "pipe set-up". Specimens were polarized at fixed potential for long-term exposure (i. e. at least after complete current and potential stabilization). 

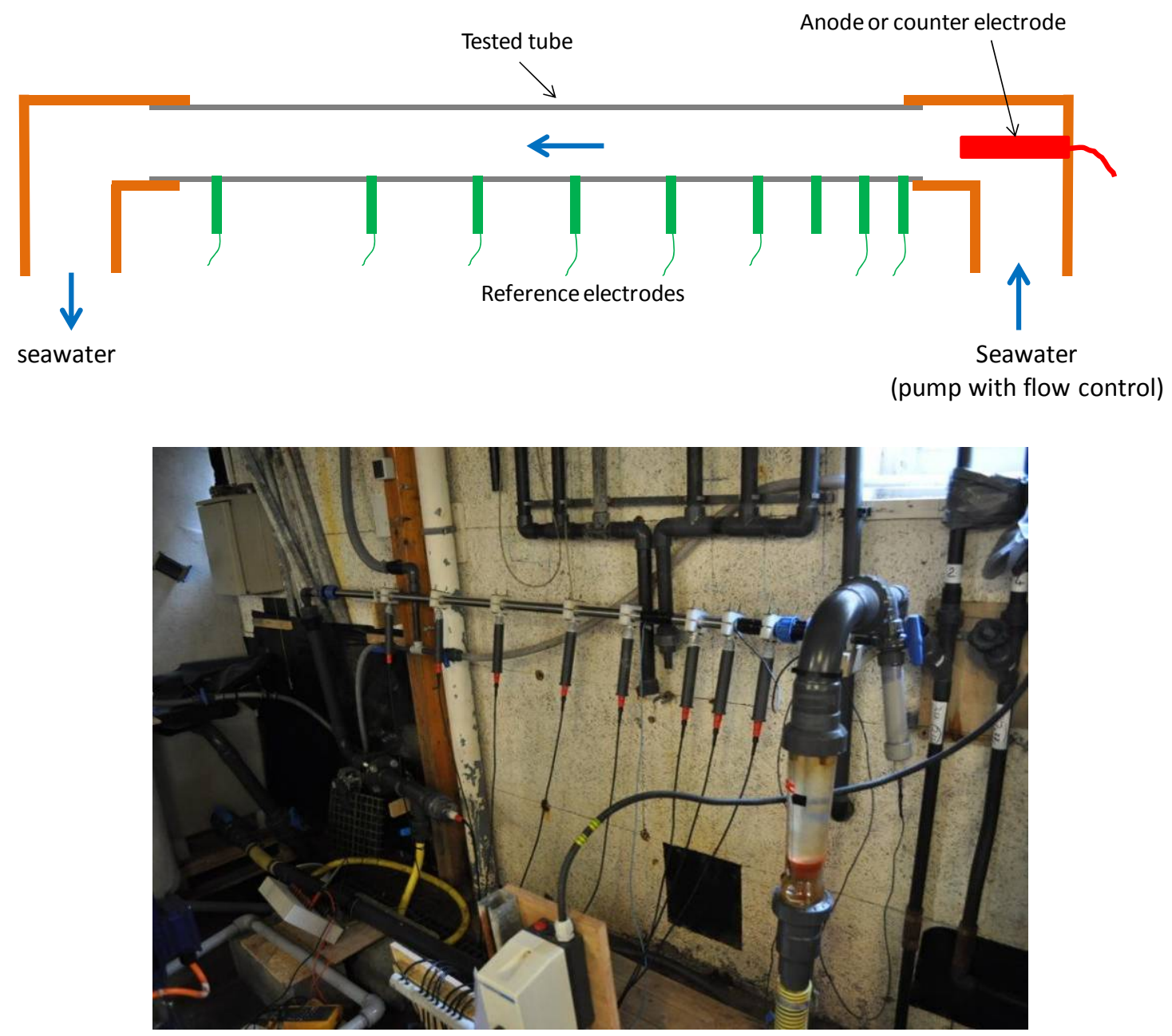

Figure 3: Schematic drawing and photograph of the 2 m-long monitored superduplex stainless steel pipe

A photograph of the tested 316L stainless steel butterfly valve is given in Figure 4 . The butterfly valves were mounted in a similar seawater loop as the one described for tube testing, allowing flow rate control and implementation of cathodic protection and monitoring (potential and current) systems. A photograph of set-up (seawater loop) for valve exposure is given in Figure 5. 


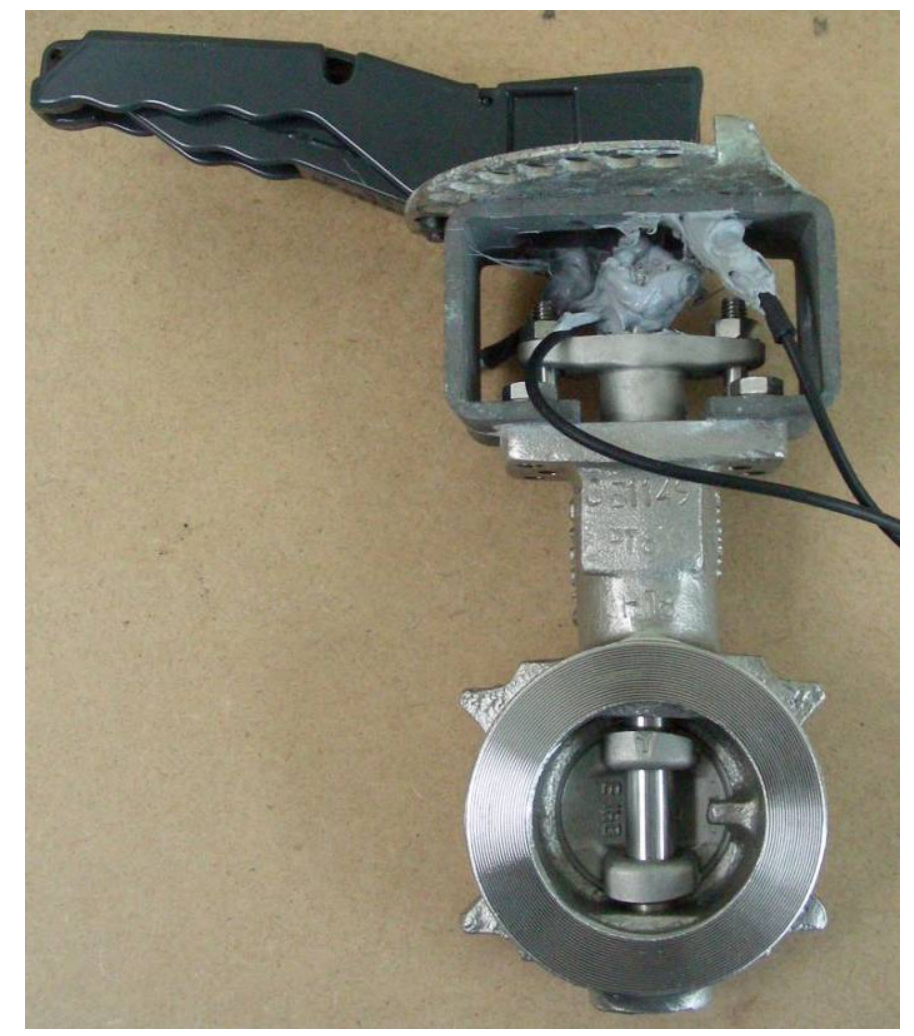

Figure 4: Photograph of the 316L butterfly valve before exposure

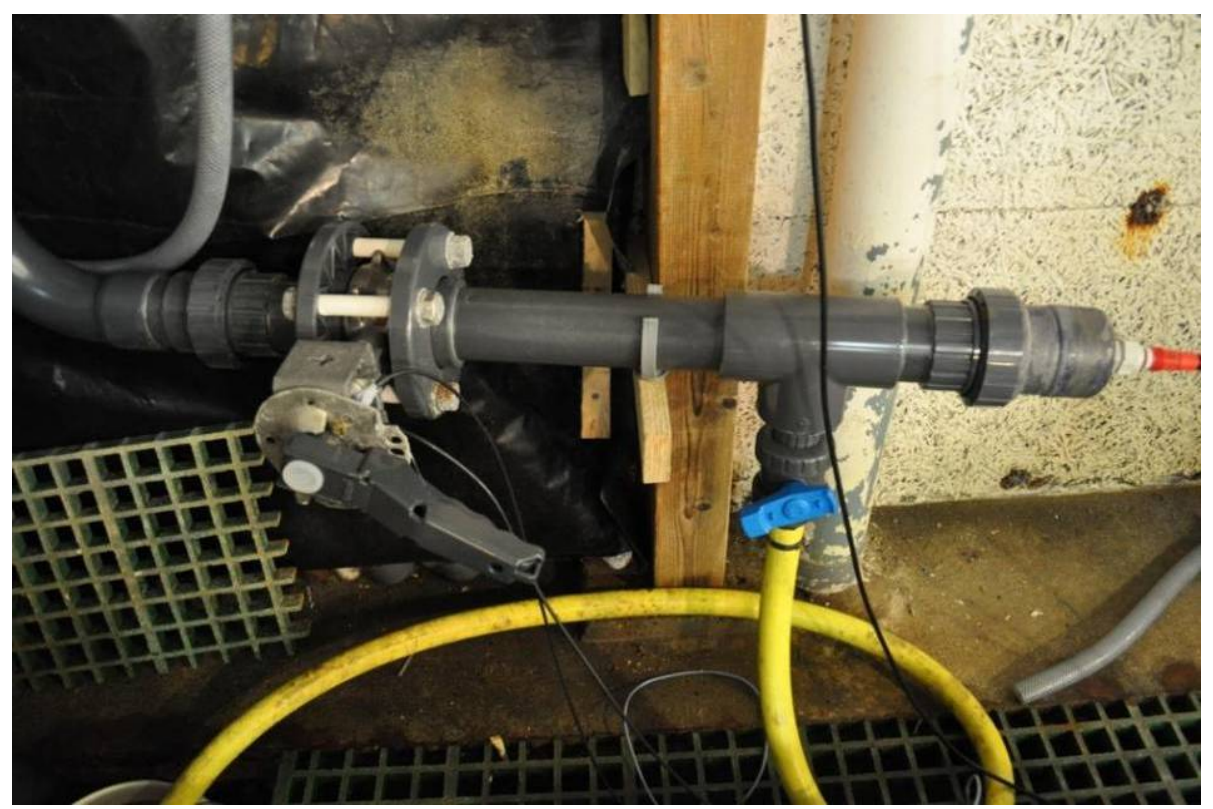

Figure 5: Photograph of the 316L butterfly valve in the set-up

For each testing condition and each tested device (pipe, valve, plate coupons and pump) measurements were repeated at least 3 times to allow statistical results. Natural seawater from the bay of Brest (France) was used for the laboratory exposures. The salinity was $35 \%$ and $\mathrm{pH}$ was 8,1 . The temperature control of the seawater was performed with regulated titanium heater, allowing a continuous control of the temperature with precision of $\pm 1^{\circ} \mathrm{C}$. 
The seawater used in the seawater loops is either natural or chlorinated at a level of $0.5 \mathrm{ppm}$ of free chlorine content. The chlorination was obtained with an electrolysis of the seawater between two keramox ${ }^{\circledR}$ coated electrodes connected to a regulated power supply. Wallace \& Tiernan units Depolox 4 \& MFA Cl2++ were used for the control of the chlorine content at $0.50 \mathrm{ppm} \pm 0.1 \mathrm{ppm}$. The chlorination level was recorded from the Depolox units which was weekly calibrated with a manual chlorine content measurement performed with a Wallace \& Tiernan P15plus spectrometer unit. The open-circuit potentials (OCP) and galvanic currents were measured and recorded as detailed in chapter 2.2.1.

\section{Field measurements}

The field results are coming from monitored cathodic protection system installed in a desalination plant in Ashkelon desalination plant in Israel. Zinc galvanic anodes were already installed on the stainless steel pipes and on stainless steel pumps. The concerned pipes were made of superaustenitic stainless steel UNS S31254 and the concerned pump was made of cast duplex UNS J92205. The chemical compositions are given in Table 3.

Table 3: Composition of the investigated pipes and pump in Ashkelon desalination plant

\begin{tabular}{|c|c|c|c|c|c|c|}
\hline & UNS. & Ni & Cr & Mo & Cu & N \\
\hline SASS Pipes & S31254 & 18.1 & 19.9 & 6.0 & 0.68 & 0.2 \\
\hline $\begin{array}{c}\text { High Pressure } \\
\text { Pump }\end{array}$ & J92205 & 5.5 & 22.0 & 2.9 & - & 0.1 \\
\hline
\end{tabular}

The cathodic protection system was initially installed by an external company who used the RCP method [15]. The initial design and implementation of the CP system was anterior and completely independent from the present program. Photographs of the installed cathodic protection by galvanic anodes are given in Figure 6 and in Figure 7 for a "protected" pipe and a "protected" pump, respectively. The protected pipes have diameters from 32" to 12", all protected with zinc galvanic anodes with initial diameter of $131 \mathrm{~mm}$. Depending on the protected pipes, the distance between two consecutive anodes is 20 to $25 \mathrm{~m}$, with one pseudoreference electrode located at equal distance between 2 consecutive anodes for potential monitoring.

The pump is "protected" with 4" zinc galvanic anodes mounted on the pipes which connect the pump (Figure 7). In the frame of the present program, a specific high-pressure bearing pseudo-reference (measurement) electrode and access fitting was specifically designed to allow the potential monitoring inside the pump (see Figure 8). 


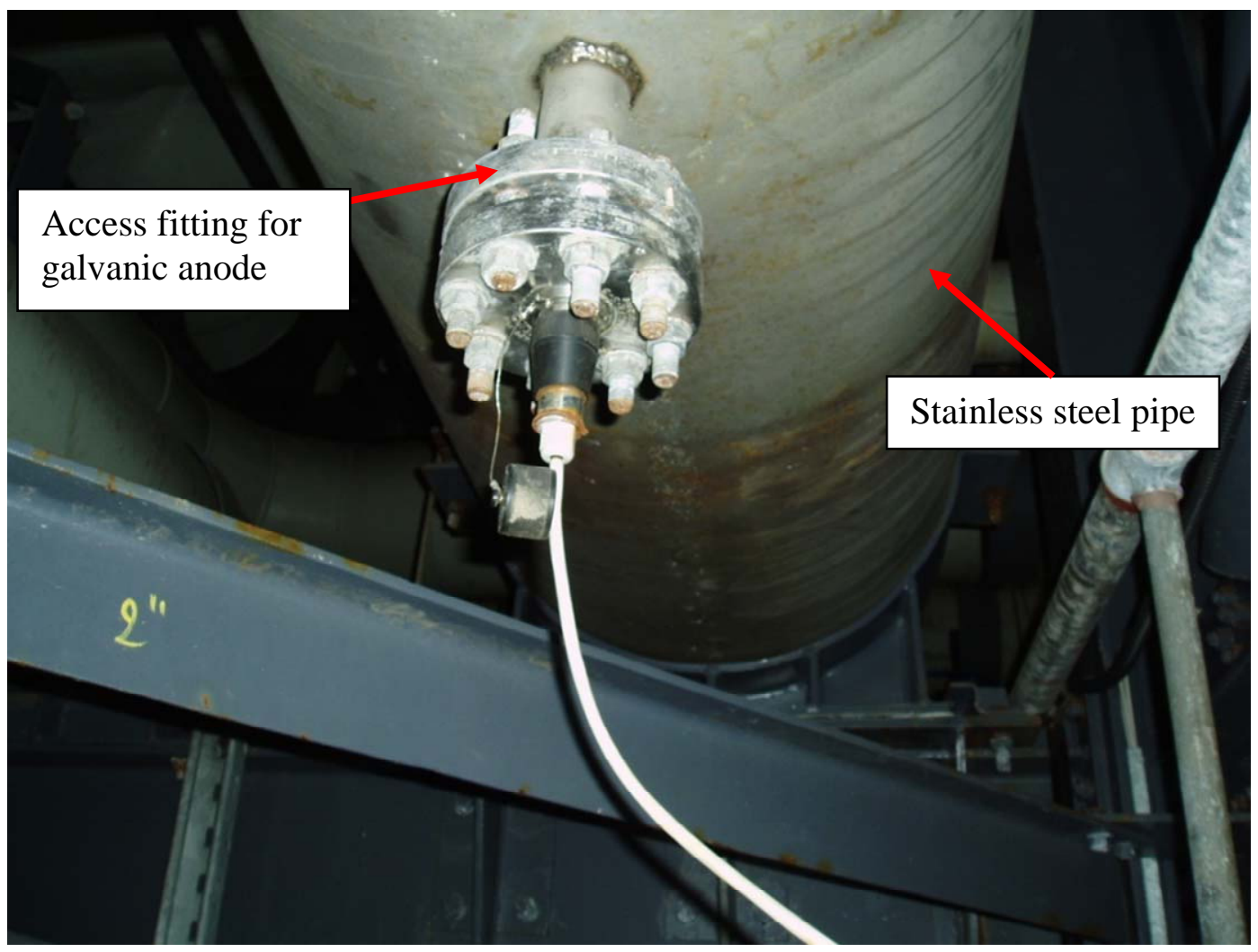

Figure 6: Stainless steel pipe with galvanic anode cathodic protection system

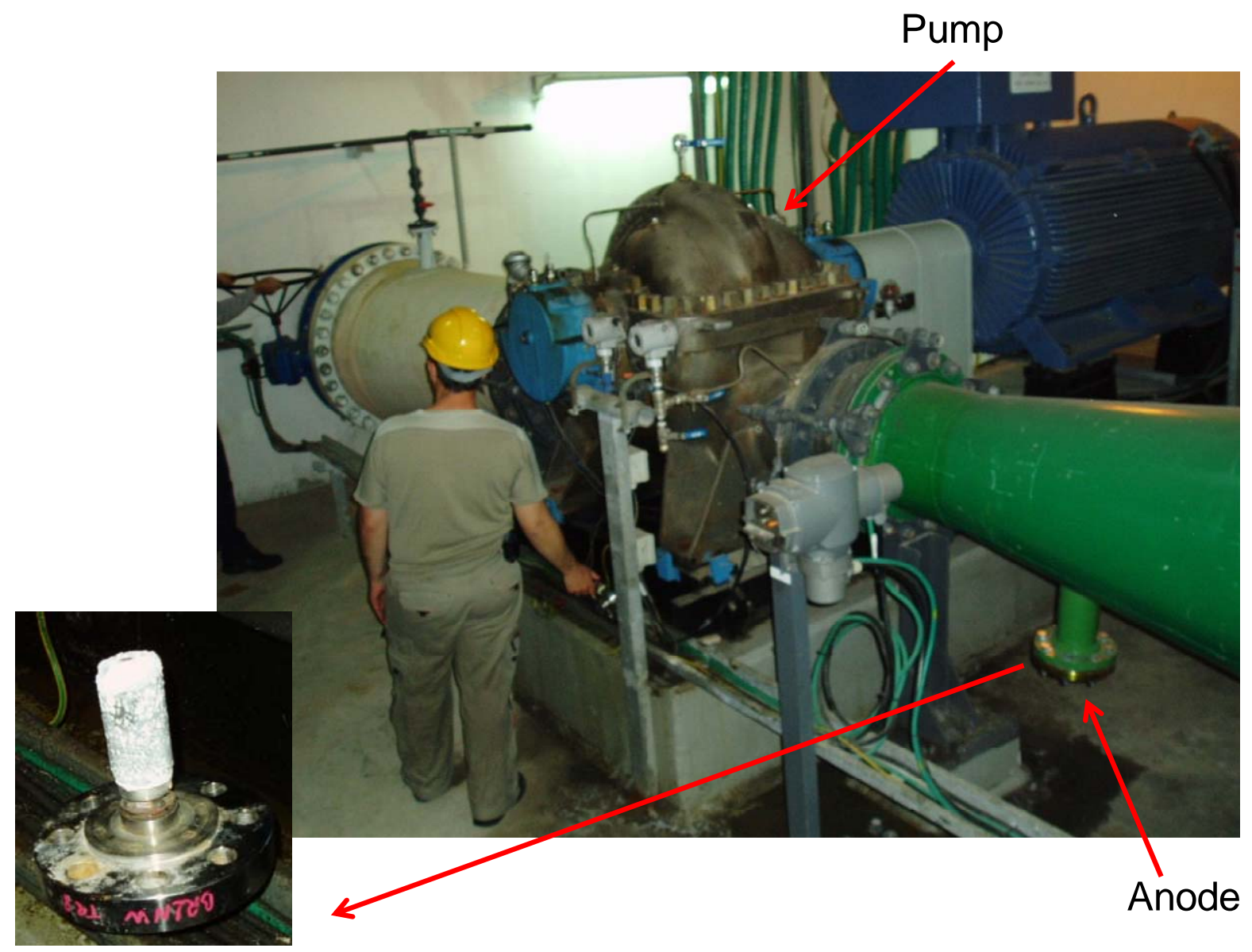

Figure 7: Stainless steel pump with galvanic anode cathodic protection system 


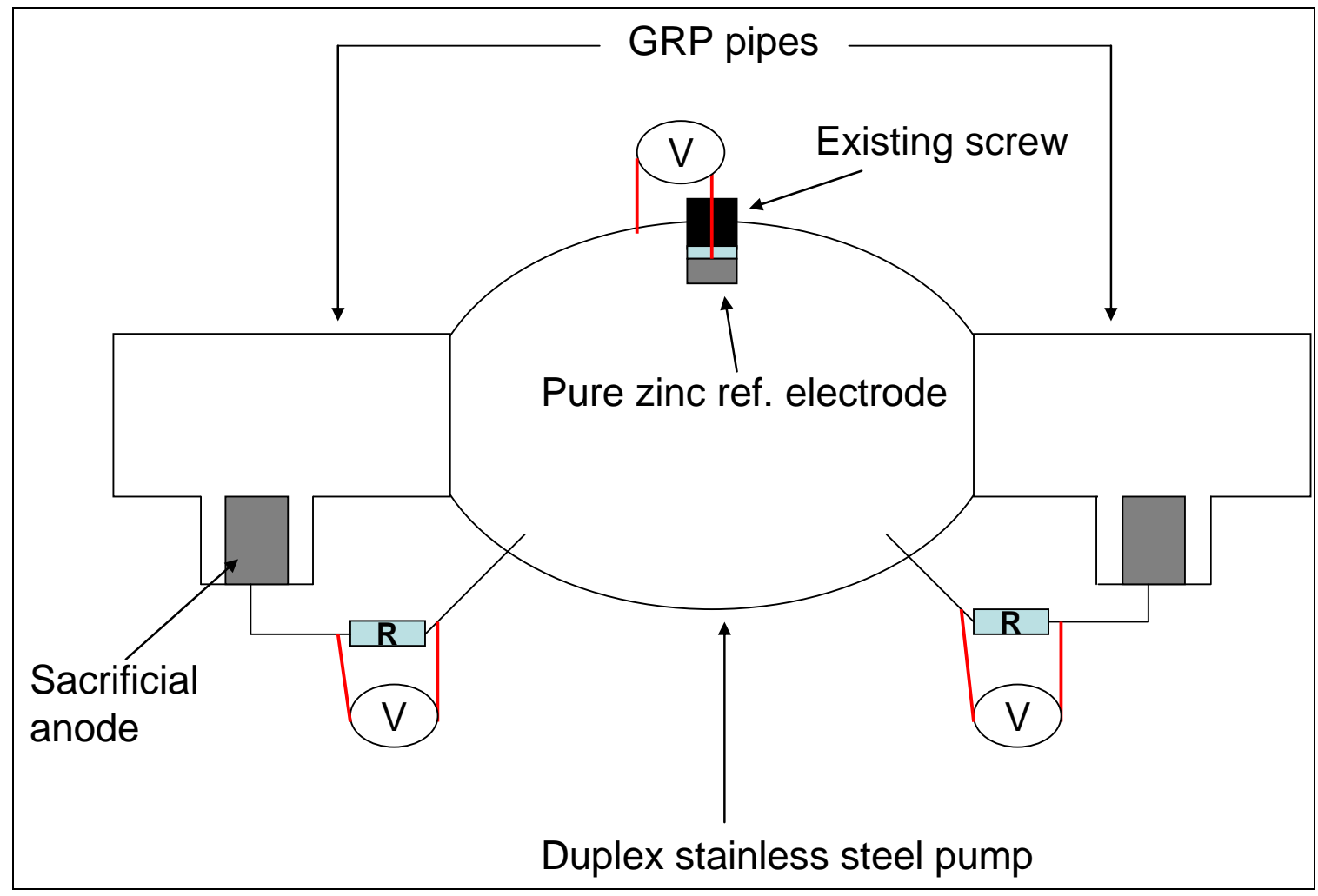

Figure 8 : Cathodic protection monitoring of a high pressure pump

\section{3-Modelling with PROCOR ${ }^{\mathrm{TM}}$ software}

The PROCOR ${ }^{\mathrm{TM}}$ software was developed by CETIM with 4 partners: IFREMER, TOTAL, DGA, and DCNS to design cathodic protection systems of underwater structures. This numerical tool, based on a Boundary Element Method, computes electrochemical potentials and current densities on the structure and everywhere inside the electrolyte. By direct derivation of the electrical potential, $\mathrm{PROCOR}^{\mathrm{TM}}$ computes the Underwater Electric Potential field (UEP), the DC electric field related to corrosion, within the electrolyte.

PROCOR $^{\mathrm{TM}}$ solves the Laplace equation, checked by the electrical potential, obtained after combining the Ohm law $(j=-\sigma \nabla u)$ and the current conservation equation $(\operatorname{div}(j)=0)$.

u: electrical potential $(\mathrm{V})$,

$\mathrm{j}$ : current density $\left(\mathrm{A} / \mathrm{m}^{2}\right)$,

$\sigma:$ conductivity $(\mathrm{S} / \mathrm{m})$.

$\nabla \mathrm{u}$ : potential gradient $(\mathrm{V} / \mathrm{m})$

Boundary conditions have to be defined to allow PROCOR $^{\mathrm{TM}}$ calculation. The most important input data for calculation are:

The electrolyte conductivity $(\sigma(\mathrm{S} / \mathrm{m}))$,

The anode electrochemical behaviour:

- use of output current density for ICCP system,

- use of impressed potential or anodic polarization curve for galvanic anode cathodic protection system,

The alloy electrochemical behaviour (use of cathodic polarization curves). 
The modelling work was performed in collaboration with Ifremer. Modelling appears particularly useful in predicting and understanding potential distributions of structures with needs to be internally protected.

\section{3-RESULTS}

\section{1-Cathodic protection criteria for wrought and cast duplex stainless steel}

Criteria for cathodic protection were evaluated for wrought and cast duplex stainless steel in seawater heated at $30^{\circ} \mathrm{C}$. Potentiostatic tests were performed on specimens with CREVCORR-type assemblies as detailed in the experimental part. Wrought specimens were tested with a pressure gasket of 3 and $20 \mathrm{~N} / \mathrm{mm}^{2}$ (crevice geometry is more "severe" with high gasket pressure). Cast specimens were tested with a pressure gasket of $3 \mathrm{~N} / \mathrm{mm}^{2}$ only. Table 4 present the crevice corrosion resistance of specimens as a function of the impressed potential. For wrought duplex S32205 crevice corrosion occurred at $0 \mathrm{mV} / \mathrm{SCE}$ with gasket pressure of $3 \mathrm{~N} / \mathrm{mm}^{2}$ and at $-100 \mathrm{mV} / \mathrm{SCE}$ with gasket pressure of $20 \mathrm{~N} / \mathrm{mm}^{2}$. For cast duplex J92205, results showed crevice corrosion at $-300 \mathrm{mV} / \mathrm{SCE}$. These results show that the "protective potential" depends on the crevice geometry and the tested alloy (i. e. more severe conditions with higher gasket pressure and less corrosion resistance for cast alloys). -600 mV/SCE was a protective potential for all tested configurations. Photographs of 3 specimens are presented in Table 5.

Table 4 : Criteria for cathodic protection of wrought duplex stainless steel S32205 and cast duplex stainless steel J92205

\begin{tabular}{|c|c|c|c|}
\hline $\begin{array}{c}\text { Potential } \\
\text { [mV/SCE] }\end{array}$ & $\begin{array}{c}\text { Rolled plate } \\
\mathbf{3 N} / \mathbf{m m}^{\mathbf{2}}\end{array}$ & $\begin{array}{c}\text { Rolled plate } \\
\mathbf{2 0} \mathbf{~ N} / \mathbf{m m}^{2}\end{array}$ & $\begin{array}{c}\text { Cast plate } \\
3 \mathbf{N} / \mathbf{m m}^{\mathbf{2}}\end{array}$ \\
\hline-1100 & OK & OK & OK \\
\hline-900 & OK & OK & OK \\
\hline-700 & OK & OK & OK \\
\hline-600 & OK & OK & OK \\
\hline-300 & OK & OK & CREV \\
\hline-100 & OK & CREV & CREV \\
\hline 0 & CREV & CREV & CREV \\
\hline+50 & CREV & CREV & CREV \\
\hline
\end{tabular}


Table 5 : Photographs of 3 specimens exposed at different impressed potentials.

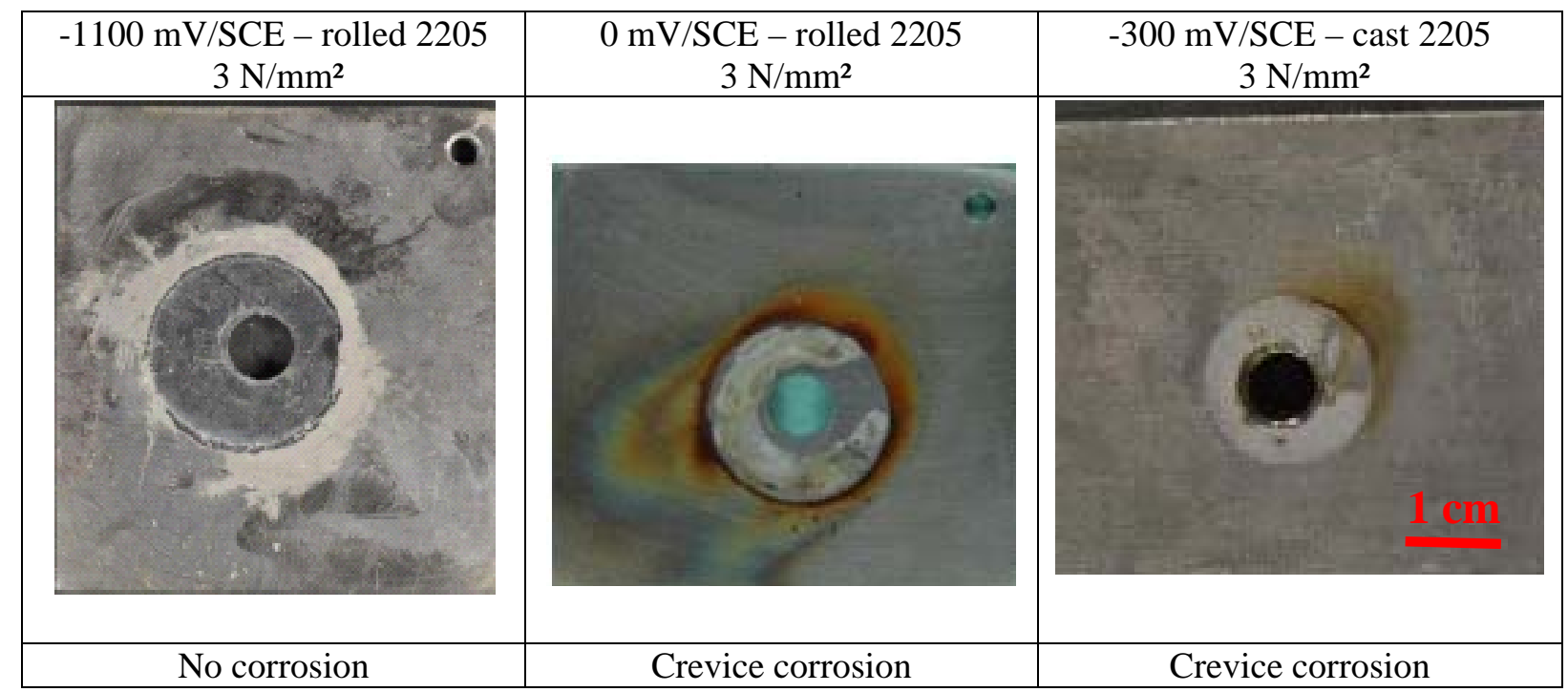

The potential of the butterfly valve was adjusted at fixed potentials with the use of potentiostat, under biofilmed conditions in natural seawater. Tested potentials ranged from -300 to $-1100 \mathrm{mV} / \mathrm{SCE}$.

After the 1 month exposure at -300 mV/SCE, some corrosion products were observed at one gasket side and the valve was removed for inspection. Photographs of the creviced valve are given in Figure 9. Severe crevice corrosion was observed on a face in contact with the gasket. After 3 months exposure at $-400 \mathrm{mV} / \mathrm{SCE}$ the stainless steel valve was inspected and corrosion was still noticed, as shown in Figure 10. The maximum corrosion depth after 3 months exposure was only $40 \mu \mathrm{m}$ at $-400 \mathrm{mV} / \mathrm{SCE}$ meaning CP significantly decreased the rates of corrosion propagation.

Photographs of 316L-valves polarized at -600 and $-1100 \mathrm{mV} / \mathrm{SCE}$ during 3 months are given in Figure 11 and Figure 12, respectively. No corrosion was found in this potential "range" which appeared to be a safe range for the tested 316L valves. From evaluation after exposure the calcareous deposit was clearly more visible and thicker when potential decreased from -600 to $-1100 \mathrm{mV} / \mathrm{SCE}$. 

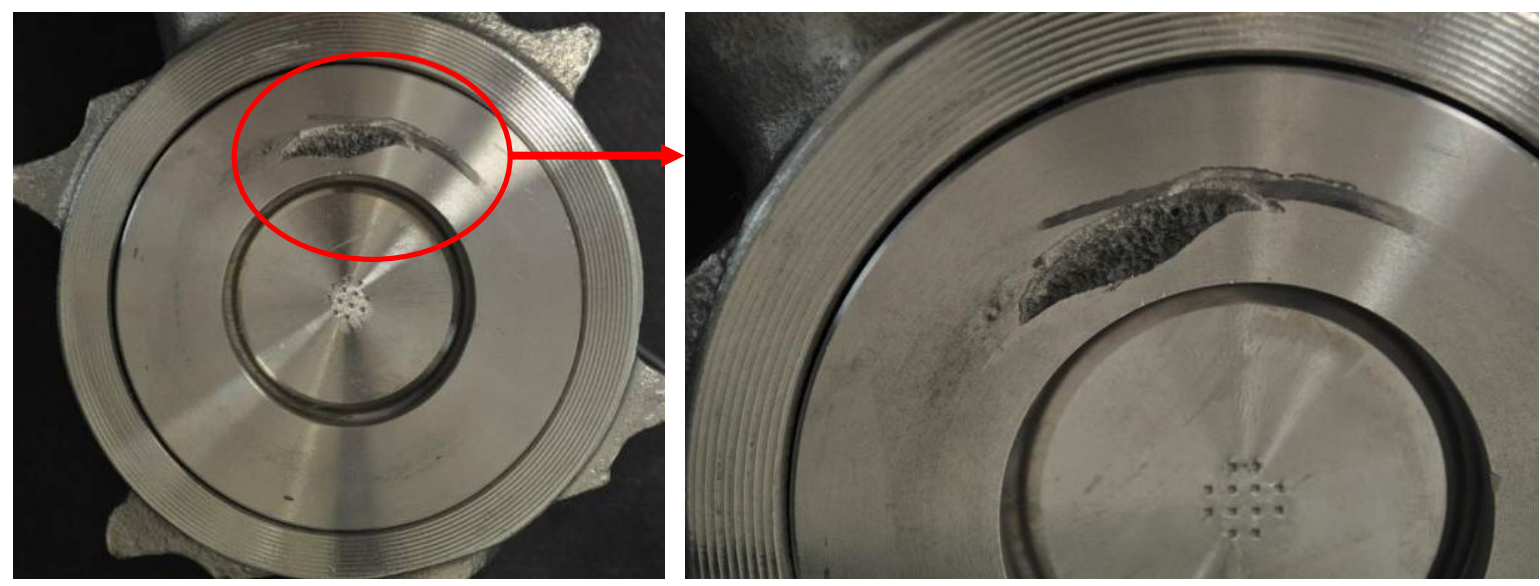

Figure 9: Photographs of butterfly valve after one month at impressed potential of -300 mV/SCE (crevice corrosion)
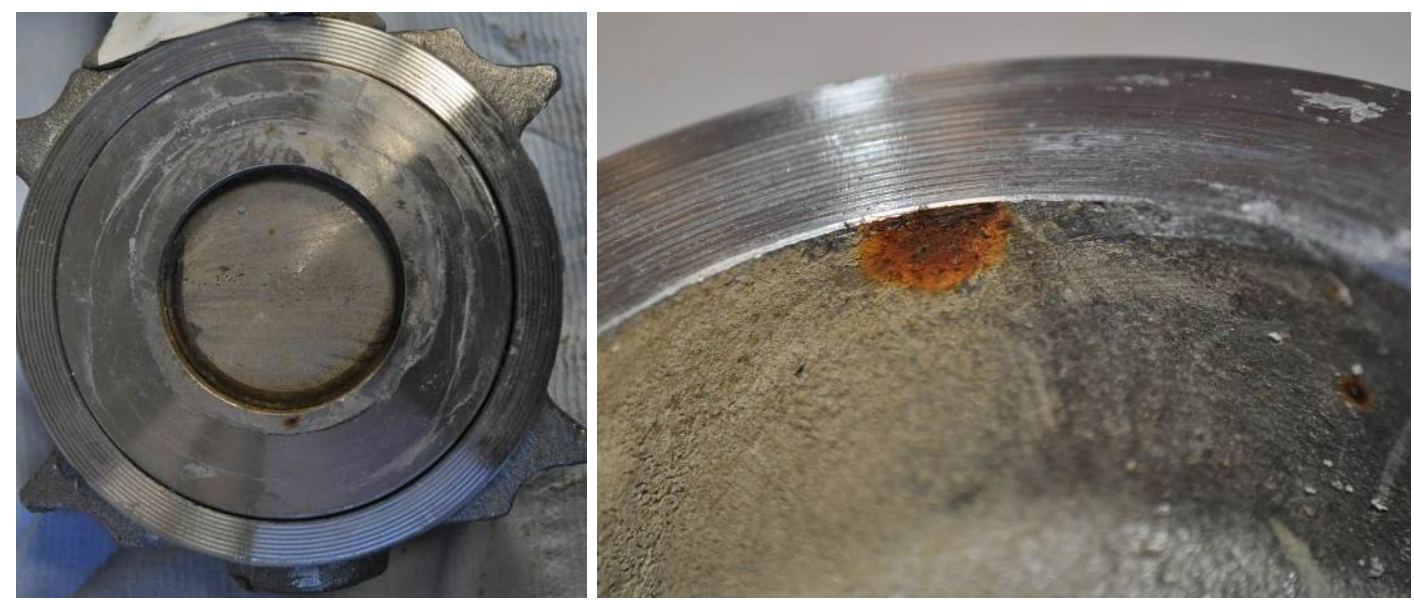

Figure 10: Photographs of butterfly valve after one month at impressed potential of -400 mV/SCE
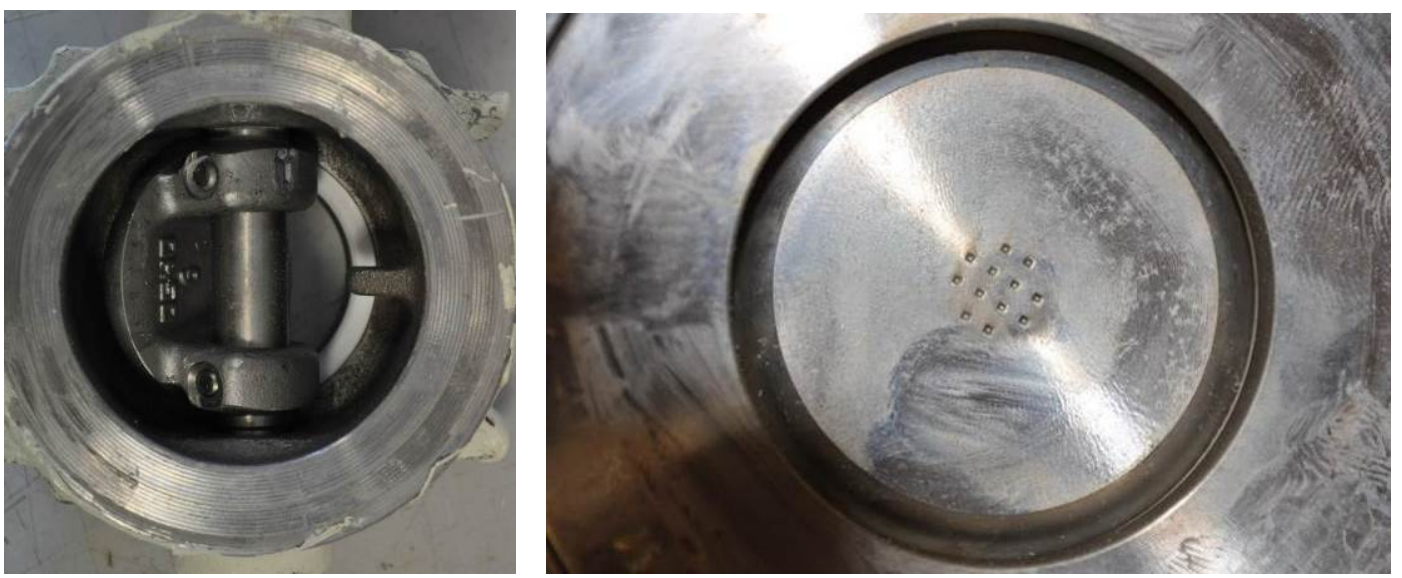

Figure 11: Photographs of butterfly valve after one month at impressed potential of -600 mV/SCE 

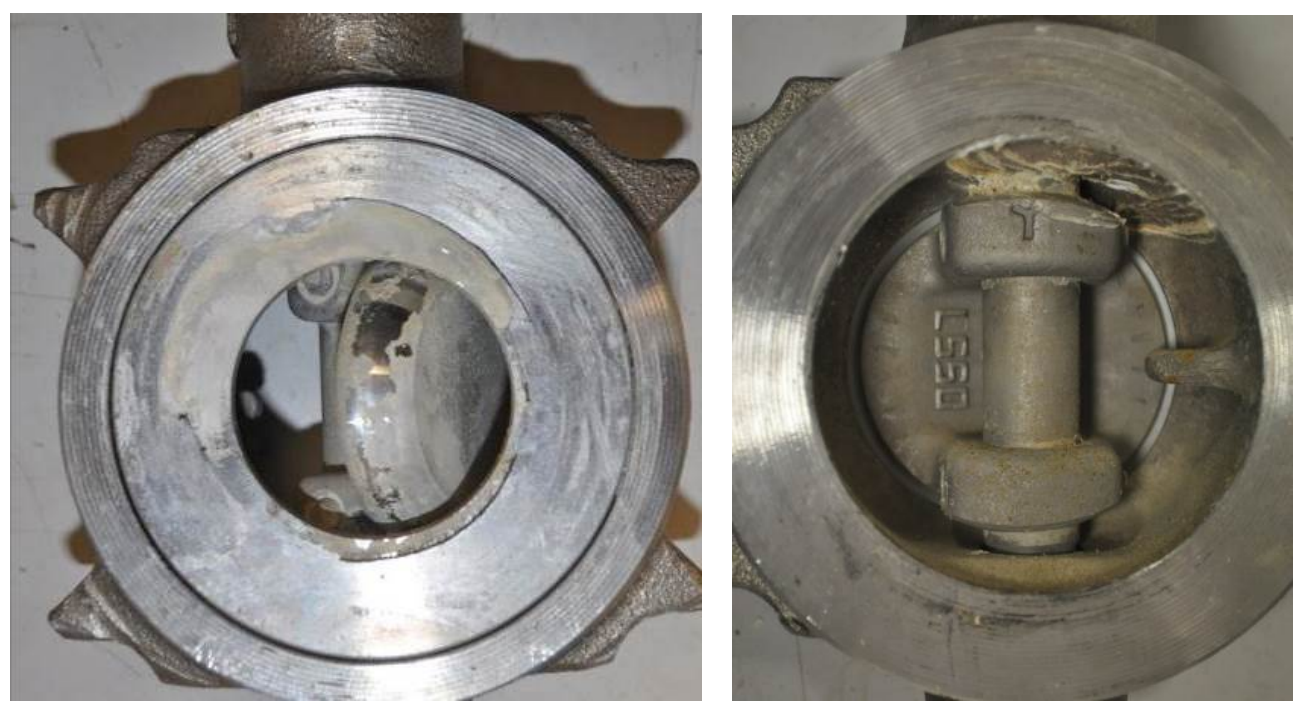

Figure 12: Photographs of butterfly valve after one month at impressed potential of -1100 mV/SCE

\section{$\underline{\text { 3.2-Polarization curves for stainless steels in SWRO service conditions }}$}

All the laboratory results were in good line whatever the tested geometries (valve, pump and plate), all the results from polarization of stainless steel components at laboratory scale are summarized in Figure 13 which draws "global polarization domains". The most important factors influencing the polarization curves of stainless steel coupons are clearly:

- Biofilm formation leading to significant increase of current demand

- Calcareous formation leading to significant decrease of current demand

The pressure did not show a significant influence on the polarization curves (no impact on cathodic protection design), showing similar values than on Figure 13 from 1 to 6 bar. 


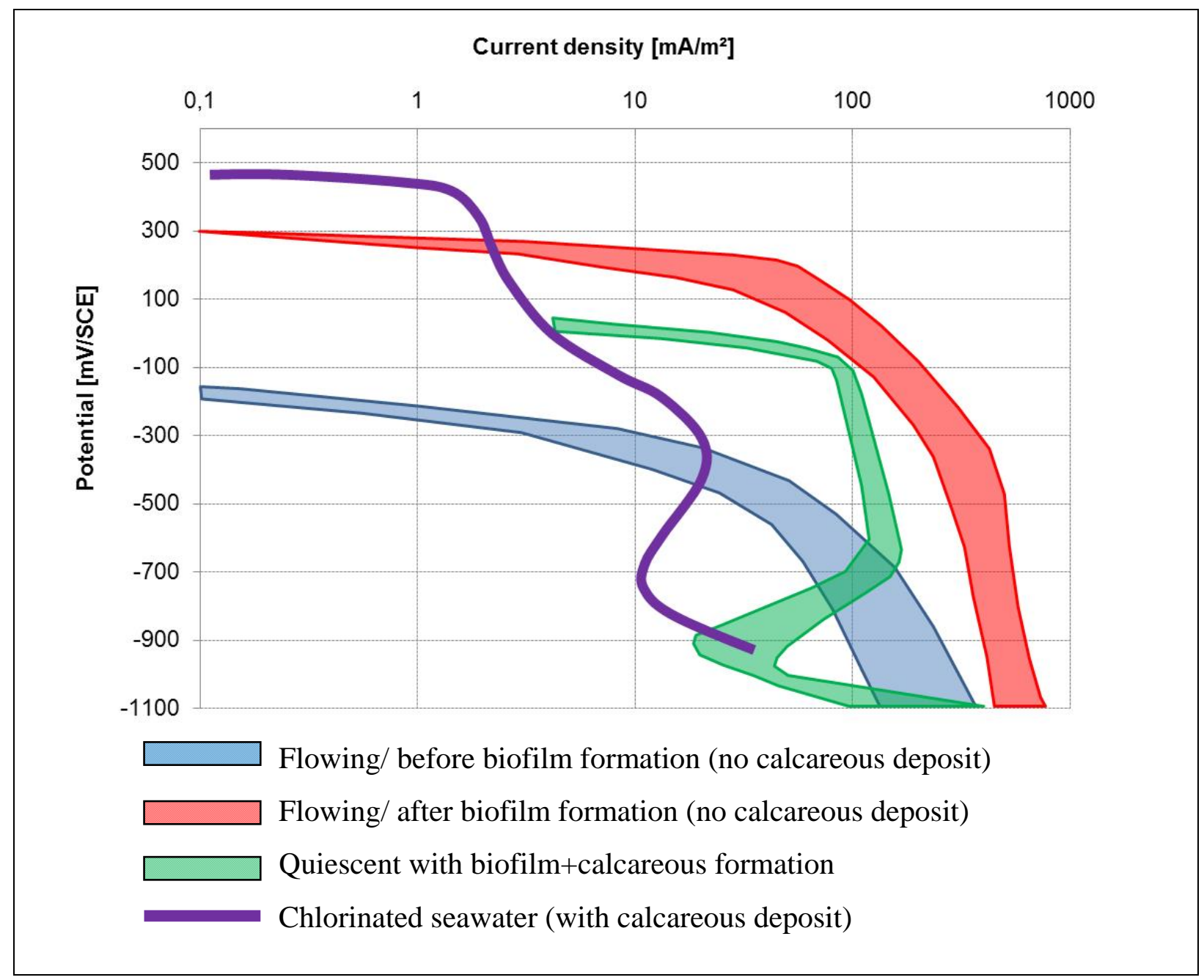

Figure 13: Range of polarization curves of stainless steel. Range of values from at least 15 measurements for each condition on various stainless steel coupons (plate, tube and valve)

\section{2-Modelling and field results}

Field potential measurements were performed in Ashkelon desalination plant on 32" and 12" stainless steel pipes, protected with a galvanic anode system. These structures were modelled with PROCOR ${ }^{\mathrm{TM}}$ for which the polarization curves obtained in the frame of this program were used (see example in Figure 14). Field and modeling results were compared both with and without biofilm (i. e. after sanitation and/or before biofilm settlement). This is shown in Figure 15 and Figure 16 for 32” and 12” pipes, respectively. In biofilmed conditions the model gives very satisfying results in comparison with the field measurements. In not biofilmed conditions, the modeled potential gradients are about $100 \mathrm{mV}$ lower than field measurements. This can be explained by the fact that in the field case, sanitation probably leads to un-perfect complete removal of biofilm and/or leads to some modification of passive layer. 


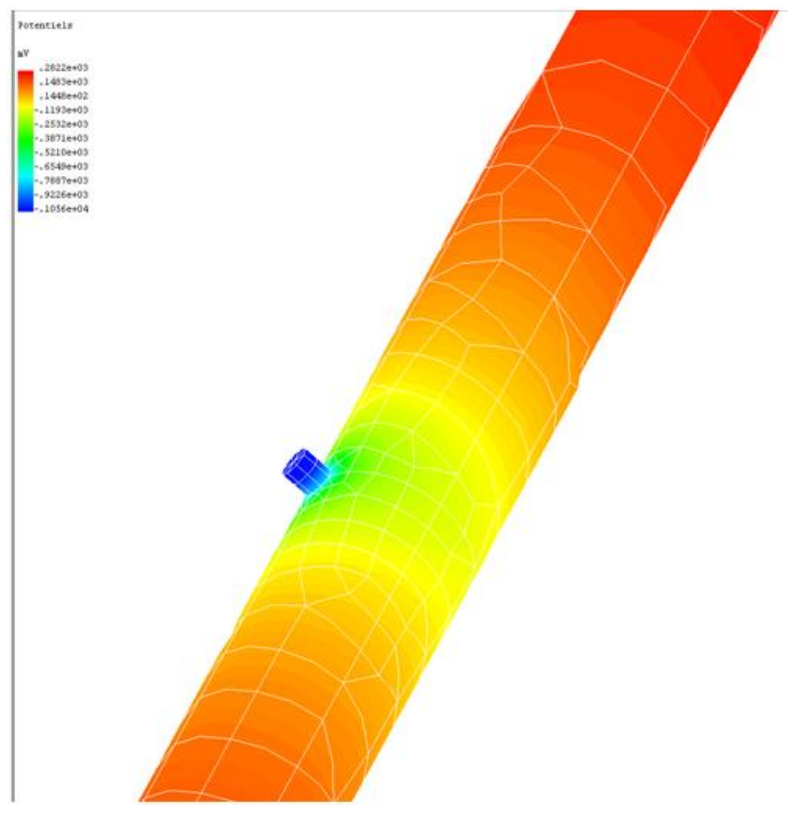

Figure 14: Modeled stainless steel pipe (32”) with zinc anode

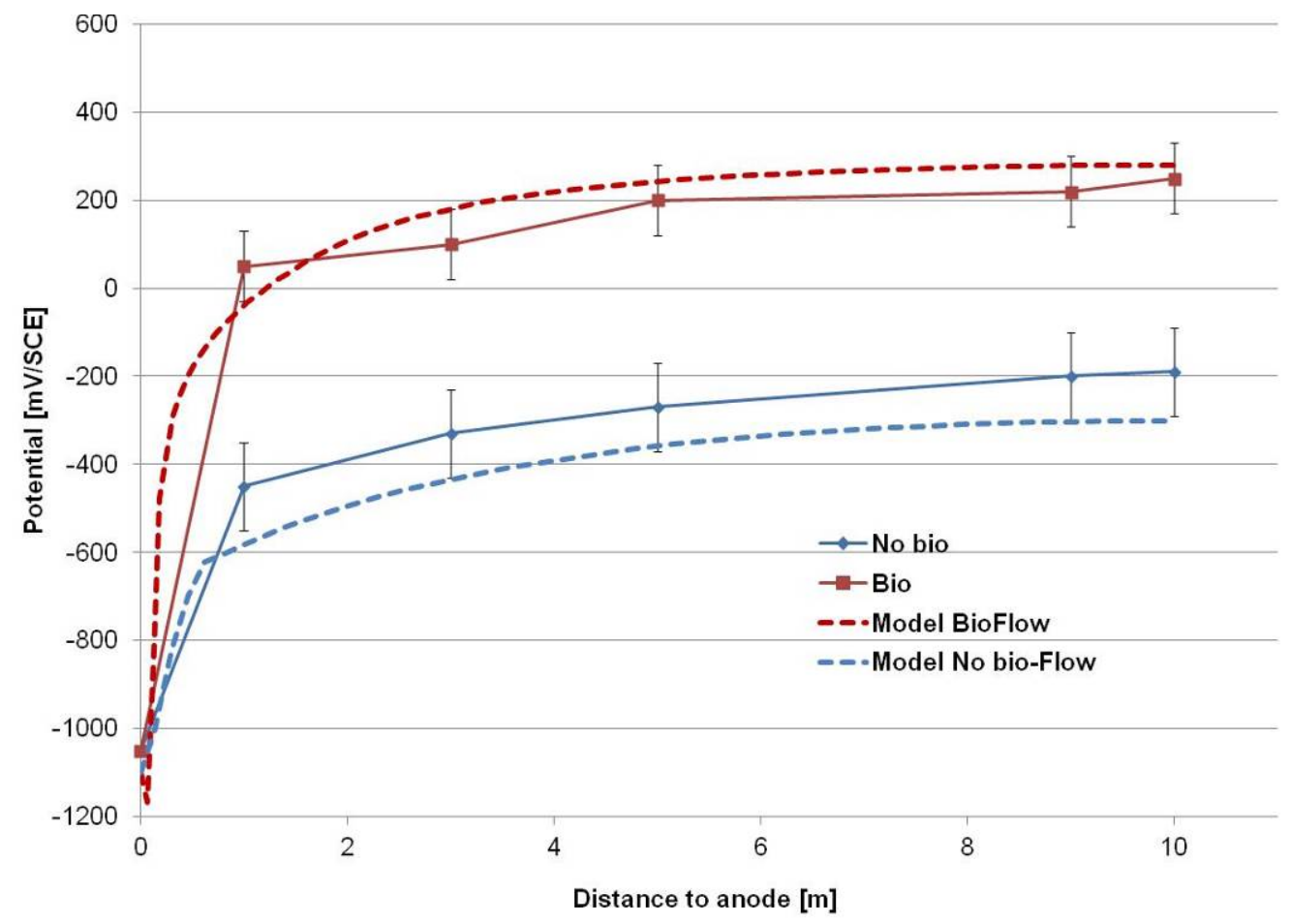

Figure 15: Potential gradient along 32'” stainless steel pipe: model versus field, with and without biofilm 


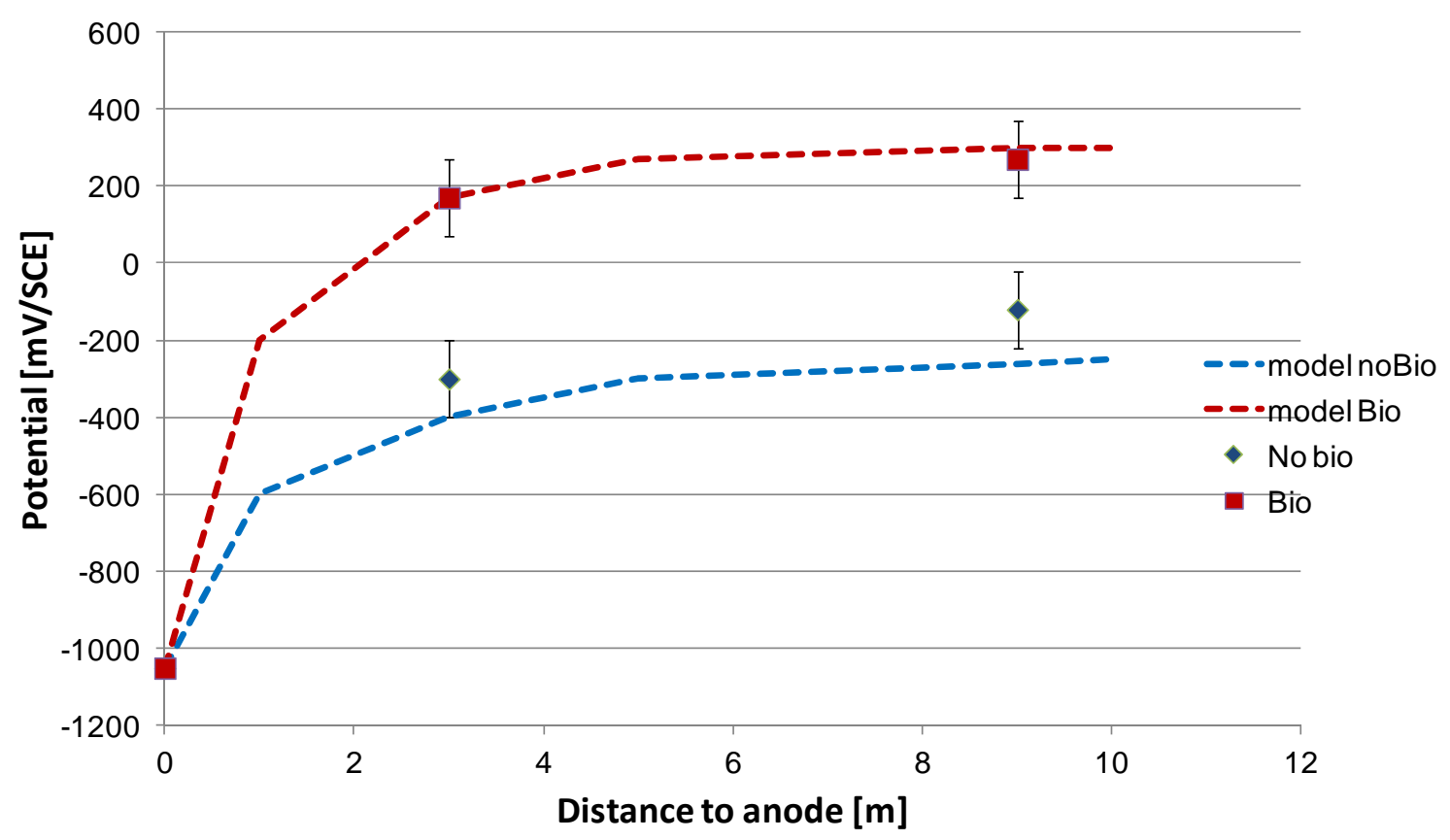

Figure 16: Potential gradient along 12"' stainless steel pipe: model versus field, with and without biofilm

With the modelling work, it was possible to study axis of improvement of cathodic protection systems, such as anode size and distance between anodes. The effect of anode size on the cathodic protection was investigated by modelling anodes more than 3 times larger to compare with "standard" anode size. Results are given in Figure 17 . For the concerned pipe, it shows that the use or 3 times-"larger" anodes allowed a decrease of about $20 \mathrm{mV}$ between two anodes when compared to "standard size" anodes. The beneficial effect is thus not significant regarding the very large size difference between the anodes.

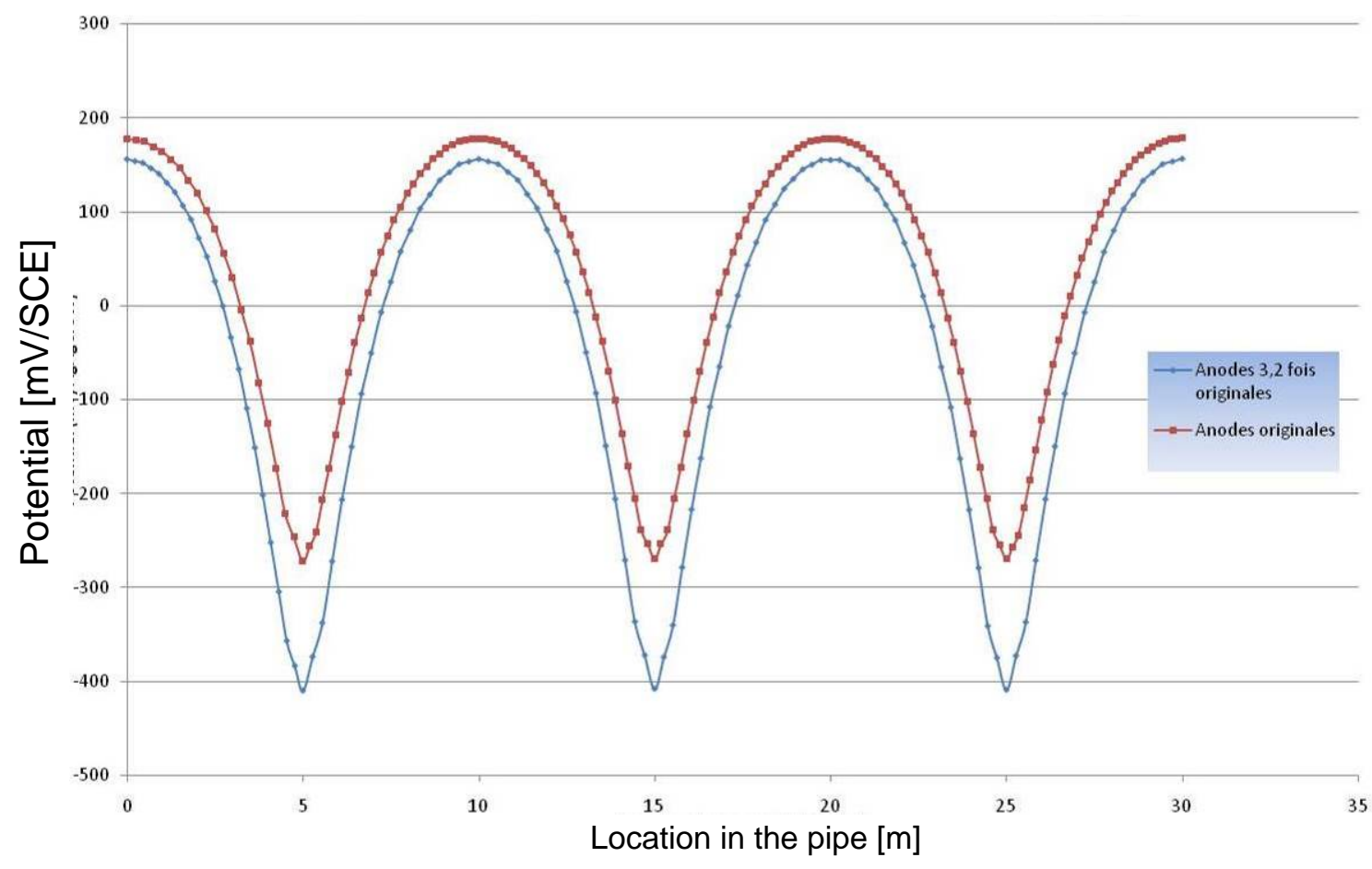

Figure 17: Effect of anode size on potential gradient along a 32” pipe in natural seawater 
The effect of distance between 2 anodes is illustrated in Figure 18 for the 12” pipes. It shows that this parameter clearly has a significant impact on the potential gradient along the pipe. The modelling allows to assess the required distance between 2 anodes to remain always below a defined potential. For instance the zones which always remains below $+100 \mathrm{mV} / \mathrm{SCE}$ are indicated in blue in Figure 19. It shows that for the modelled pipe, a distance of $5 \mathrm{~m}$ between anodes is sufficient to reach this criteria anywhere along the pipe after biofilm formation.

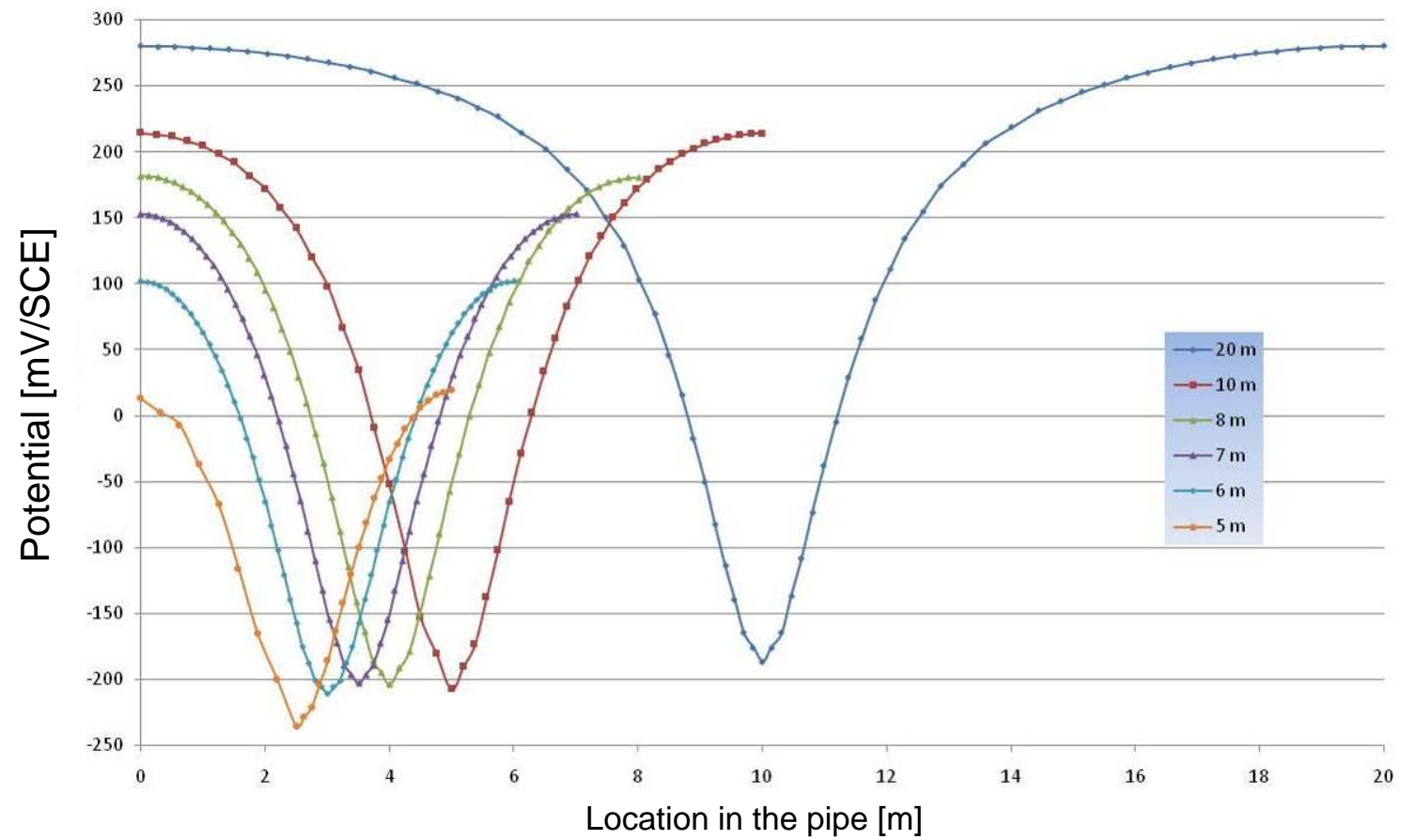

Figure 18: Effect of distance between 2 anodes on the potential gradient along a 32" pipe in natural flowing seawater 


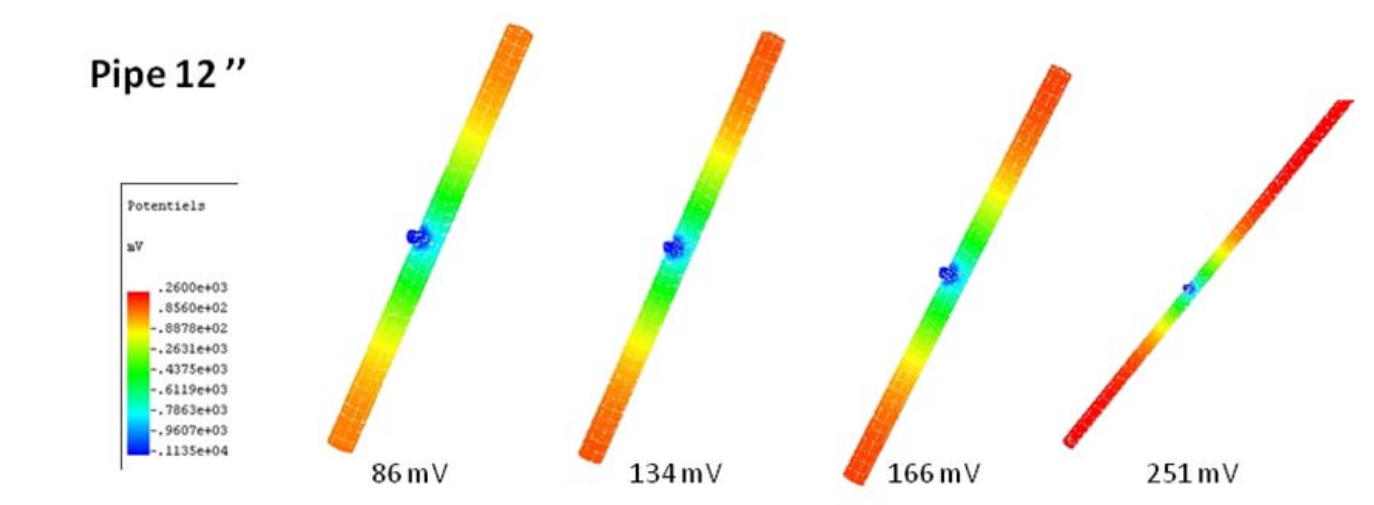

Potential $<+100 \mathrm{mV}$,
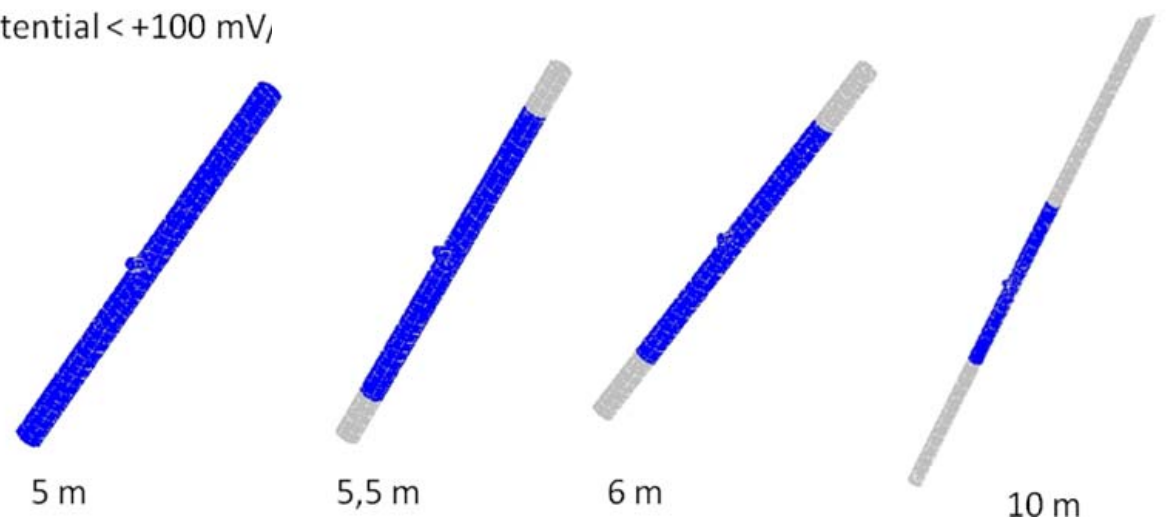

Figure 19: Potential mapping of a 12" stainless steel pipe with different anode distances and protected length (blue) with the $+100 \mathrm{mV} / \mathrm{SCE}$ criteria

With the existing CP system, the results from the monitored High Pressure pump showed that potentials were not in "protective domain", explaining the observed severe corrosion after few months of use. Regarding the current demand in presence of biofilm assessed in this study, the cathodic protection system with galvanic anodes on the concerned pump was shown to be under-designed. The corrosion was stopped by decreasing selected cathodic surfaces with adapted coating. With this system (cathodic protection + coating), the measured potential of the pump during service always remained at safe values and no corrosion occurred after 6 months of exposure.

\section{4-CONCLUSIONS}

Cathodic polarization of stainless steel for internal corrosion protection in seawater applications was investigated as a function of service conditions. Long-term cathodic polarization curves were drawn, showing a very significant influence of biofilm formation (inducing significant increase of cathodic current demand) and calcareous deposit, inducing decrease in cathodic current demand.

In addition to environmental factor, the internal geometry of the stainless steel component to be protected is a very significant influencing parameter on the efficiency of internal cathodic protection. This was shown from laboratory and field measurements in seawater handling systems with different geometries (e. g. pipes with different diameters, pumps with internal hydraulic shape, etc.) and confirmed with modelling.

Protective potentials for stainless steels were shown to depend on crevice configuration, alloy grade and product form. From the present work, a safe criteria for cathodic protection of duplex-type stainless steels and 316L-stainless steel was confirmed to be $-600 \mathrm{mV} / \mathrm{SCE}$ but it 
should be kept in mind that other stainless steel grade and/or other crevice geometries may influence cathodic protection critera.

With the collected data from "long-term" laboratory tests, the modelling results obtained with PROCOR $^{\mathrm{TM}}$ were in very good line with both laboratory and field measurements, which validates the design curves obtained in the study.

In the case of biofilmed conditions, increasing the anode size does not significantly increase the protected distance in stainless steel pipes and the most efficient way to increase the CP efficiency inside pipes is to decrease the distance between 2 anodes.

In field application, regarding the large surfaces to be protected and the very high current demand in biofilmed conditions, the only successful solution to protect a low grade stainless steel pump was to coat the pump casing, associated with cathodic protection.

\section{Acknowledgements}

RISE (Sweden), Veolia Water (France) and participants from the Member Research Consortium MRC4 (WET Corrosion) are gratefully acknowledged for financial and technical support. Ifremer is thanked for all the modelling work performed with PROCOR ${ }^{\mathrm{TM}}$. Gulnara Omarbekova from Lubriziol Advance Material is also gratefully acknowledged for the supply and advices of all pressure bearing plastic elements used in the laboratory set-up. Jean-Michel Hamoignon and Charles Leballeur from Institut de la Corrosion are acknowledged for their help in the experimental set-ups. 


\section{References}

1. Abu-Safiah A., Material Selection for the High Pressure Section of Seawater RO Plants. Desalination, 84, pp 279-308, 1991.

2. Strandmyr O. and Hagerup O., Field Experience with Stainless Steel Materials in Seawater Systems. Corrosion'98, Houston, NACE, paper Nº. 707, 1998.

3. Havn T., Material Engineering and Fabrication Experiences. paper 56, NACE CORROSION'95, 1995.

4. Johnsen R., North Sea Experience with the Use of Stainless Steel in Seawater Applications. EFC Publication 10, The Institute of Materials, 1993.

5. $\quad$ Larché N., Thierry D., Debout V., Blanc J., Cassagne T., Peultier J., Johansson E., and Taravel-Condat C., Crevice corrosion of duplex stainless steels in natural and chlorinated seawater. Duplex World 2010, Beaune, France, October 11-13, 2010.

6. Larché N. and Thierry D., Corrosion performance of $25 \% \mathrm{Cr}$ superduplex stainless steel for different seawater applications. Stainless Steel World, Maastricht, The Netherlands, 2011.

7. Yakuwa H., Miyasaka M., and Sugiyama K., Evaluation of Crevice Corrosion Resistance of Duplex and Super Duplex Stainless Steels for Seawater Pumps. Corrosion, NACE Paper N. 09194, 2009.

8. Recommended Practice DNV-RP-B401 - Cathodic Protection Design, 2005.

9. ISO 15589-2:2004, 2004.

10. General Principle of Cathodic Proptection in Seawater. Standard NF EN 12473, 2000.

11. http://www.protectioncathodique.net.

12. N. Larché, P. Dézerville, D. Le Flour, Corrosion and Corrosion Management Investigations in Seawater Reverse Osmosis Desalination Plants, Desalination and Water Treatment, Volume 51, Issue 7-9, February 2013, pages 1744-1761

13. Espelid B., Development of a New Crevice Corrosion Qualification Test for Stainless Steels. Stainless Steel World, 2003.

14. Kivisakk U., Crevice Corrosion Testing of Stainless Steel Tubes. Corrosion'04, 2004. 15. Johnsen R., Gartland P. O., Valen S., and Drugli J. M., Internal Cathodic Protection of Seawater Piping System by the Use of RCP Method. NACE Corrosion, Paper 559, 1996. 